DOI - https://doi.org/10.5965/2316796309172020122

\title{
Requisitos para projetos de computação vestivel para crianças autistas com base no Design Centrado no Humano
}

Carla Feder Wick ${ }^{1}$

Anna Luiza Moraes de Sá Cavalcanti ${ }^{2}$

Giselle Schmidt Alves Díaz Merino ${ }^{3}$ João Eduardo Chagas Sobral ${ }^{4}$ 


\section{Resumo}

O autismo é uma síndrome caracterizada por alterações na comunicação, na interação social e na imaginação. A percepção da falta de informação, - preconceito e a oportunidade de utilizar novas tecnologias para melhorar a qualidade de vida de crianças autistas, pautaram a pesquisa aplicada desenvolvida no mestrado profissional em design, que gerou uma proposta conceitual de computação vestível por meio da abordagem metodológica do Design Centrado no Humano. Este artigo é um recorte dessa investigação e relata a pesquisa de campo, cujos dados levantados foram analisados e sintetizados em requisitos para projeto de computação vestível. A pesquisa foi submetida ao Comitê de Ética e aprovado com o protocolo $\mathrm{n}^{\circ} 81167917.6 .0000 .5366$. Os requisitos para projetos de artefatos de computação vestível, destinado ao auxílio de crianças autistas, fazem parte dos resultados alcançados e espera-se que contribuam para além das soluções formais, estéticas e tecnológicas, com atributos que consideram os aspectos subjetivos, emocionais e perceptivos em projetos destinados a esse público alvo.

Palavras-chave: Design Centrado Project Requirements; Wearable; Autistic no Humano; Requisitos de Projetos; Child;

Computação Vestível; Criança Autista;

ISSN: 2316-7963

${ }^{1}$ Mestre em Design, Univille (carla_feder@hotmail.com)

${ }^{2}$ Mestre em Design, IED (anna.cavalcanti08@gmail.com)

${ }^{3}$ Doutora em Engenharia, UFSC (gisellemerino@gmail.com)

${ }^{4}$ Doutor em Design, PUC-RJ (sobral41@gmail.com)

\section{Introdução}

Segundo a OMS (Organização Mundial da Saúde), 10\% da população mundial possui algum tipo de deficiência permanente ou temporária. No Brasil são 45 milhões de pessoas e em Santa Catarina esse número ultrapassa 1,3 milhões, o que requer uma atenção sobre a inclusão (IBGE, 2010). Quando se trata do TEA (Transtorno do Espectro Autista), estima-se que existam 70 milhões de pessoas no mundo, que segundo a Organização das Nações Unidas (ONU, 2016), representa 1\% da população mundial, ou seja, uma em cada 68 pessoas. O National Health Statistics Report, em 2013, publicou um estudo sobre o autismo nos Estados Unidos da América em que em cada 50 crianças nascidas, uma possui esse transtorno (PINHO, 2015). No Brasil, estima-se que existam 2 milhões de pessoas com TEA (IBGE, 2010) e que sofrem com discriminação e atendimento inadequado.

Ao longo dos últimos anos, houve muitos estudos sobre o comportamento e características da criança com TEA. Alguns foram iniciados por Kanner em 1943, mas trata-se, historicamente, de um diagnóstico recente e tema atual. O autismo é um transtorno do desenvolvimento que afeta três áreas especificas: socialização, comunicação e comportamento. (SILVA, 2012)

No processo de desenvolvimento do ser humano é relevante, como destaca Vygotsky (1987), o processo de apropriação do indivíduo de experiências presentes na sua cultura, com ênfase na ação, linguagem e processos interativos para a construção de estruturas mentais superiores. Para o ser humano com limitações, como no autismo, em que as dificuldades estão relacionadas com as estruturas mentais e seu desenvolvimento, pode ocorrer uma barreira de aprendizado e evolução.

O autismo é uma síndrome (diferente de doença) caracterizada por alterações e desvios na comunicação, na interação social e na imaginação em idade muito precoce, geralmente antes dos três anos de idade. Esses três desvios caracterizam esse transtorno e são considerados como a 'Tríade', responsável por um padrão restrito e repetitivo de comportamento, variando os níveis de inteligência de retardo mental acima da média. (MELLO, 2007)

Mello (2004) relata que o autismo também é caracterizado por problemas de comunicação na linguagem verbal e/ou não verbal. Desordens na comunicação podem ocorrer em diversos níveis e comprometer habilidades verbais e não verbais. Algumas crianças autistas não desenvolvem a habilidade de comunicação e outras apresentam linguagem imatura evidenciada por repetições, entonações, ecolalias ${ }^{1}$ e outras características de comunicação.

O diagnóstico depende de vários fatores, sendo o principal a gravidade da disfunção cerebral e seus efeitos sobre a cognição, a comunicação e o comportamento. Comumente é realizado uma investigação clínica para diagnosticar o autismo, porém não existe um marcador biológico que identifique o distúrbio por meio de exames laboratoriais. (SCHWARTZMAN, 2003; GAUDERER, 1997)

Os estudiosos afirmam que o autismo não tem cura, pois mesmo com avanços no desenvolvimento, suas características permanecem durante sua vida. Assim, existem tratamentos que ajudam a criança a ter um excelente desenvolvimento e qualidade de vida, e o ideal é que ocorram em intervenções precoces. (MELLO, 2007)

O desenvolvimento de recursos de acessibilidade e a tecnologia são também 1 Ecolalia: repetição automática que alguém faz de palavras ou frases ditas por outra pessoa, que pode constituir sintoma de perturbações neurológicas ou do desenvolvimento como, por exemplo, o autismo. (Infopedia, web, 2019) 
aliadas no tratamento e desenvolvimento da criança autista. Naoe (2012) afirma que a atração de crianças autistas por dispositivos tecnológicos é muito relatada por pais e médicos. Dispositivos eletrônicos, aplicativos e ferramentas tecnológicas podem ser utilizadas para neutralizar as barreiras e inserir o indivíduo autista na sociedade.

Os avanços tecnológicos, principalmente em razão da quarta revolução industrial, com o surgimento da Internet das Coisas, proporcionam conectividade entre os mais diversos objetos, e corrobora para a disseminação da computação vestível, sendo possível utilizá-la em artefatos que auxiliem pessoas com necessidades especiais, incluindo crianças autistas.

A percepção da falta de informação das pessoas em lidar com o TEA, o preconceito com as crianças autistas e a oportunidade de utilizar novas tecnologias para melhorar o cotidiano e a qualidade de vida de crianças com TEA, pautaram a pesquisa desenvolvida no mestrado profissional em design, que gerou uma proposta conceitual de computação vestível.

Com base no exposto, este artigo aborda um recorte dessa pesquisa e tem por objetivo apresentar os requisitos para projeto de computação vestível a partir das necessidades e dificuldades perceptivas, físicas e emocionais, enfrentadas por pais e crianças autistas em seu cotidiano, identificadas na pesquisa de campo. Foi utilizada a abordagem do Design Centrado no Humano (DHC) que leva em consideração os interesses e necessidades do usuário, colocando-o centro do projeto.

\section{Metodologia}

Os procedimentos metodológicos adotados na pesquisa foram provenientes da abordagem do DHC e do Design Centrado no Usuário, estudadas por Abras, C., MaloneyKrichmar, D., Preece, J. (2004); Garret (2010); IDEO (2009).

O DHC utiliza-se de técnicas para comunicar, interagir e promover o envolvimento de pessoas, a fim de entender seus desejos, anseios e necessidades, que muitas vezes não é perceptível por elas (KRIPPENDORFF 2000).

A IDEO, empresa americana conhecida mundialmente por aplicar a metodologia centrada no humano com seus clientes, desenvolveu uma série de ferramentas estruturadas no livro/manual denominado Human Centered Design (HCD) - Kit de Ferramentas. $O$ processo do HCD se inicia com o desafio estratégico e segue por três etapas principais: Ouvir (Hear), Criar (Create) e Implementar (Deliver). (IDEO, 2009)

O usuário é o maior detentor de conhecimento dele mesmo, sendo muito importante ouvi-lo. Na etapa ouvir, a equipe de Design realiza a coleta de histórias do usuário por meio de pesquisas de campo. Os objetivos da etapa ouvir são: determinar quem deve ser abordado; ganhar empatia; coletar histórias (IDEO, 2009).

A pesquisa com os responsáveis pelas crianças autistas, foi parte da etapa Ouvir, foco deste artigo. O método escolhido para realizar a coleta de dados foi a entrevista guiada semiestruturada e a observação de sessão terapêutica, cujos procedimentos são apresentados na figura 1.
Figura 1: Etapa OUVIR: Ações e Procedimentos

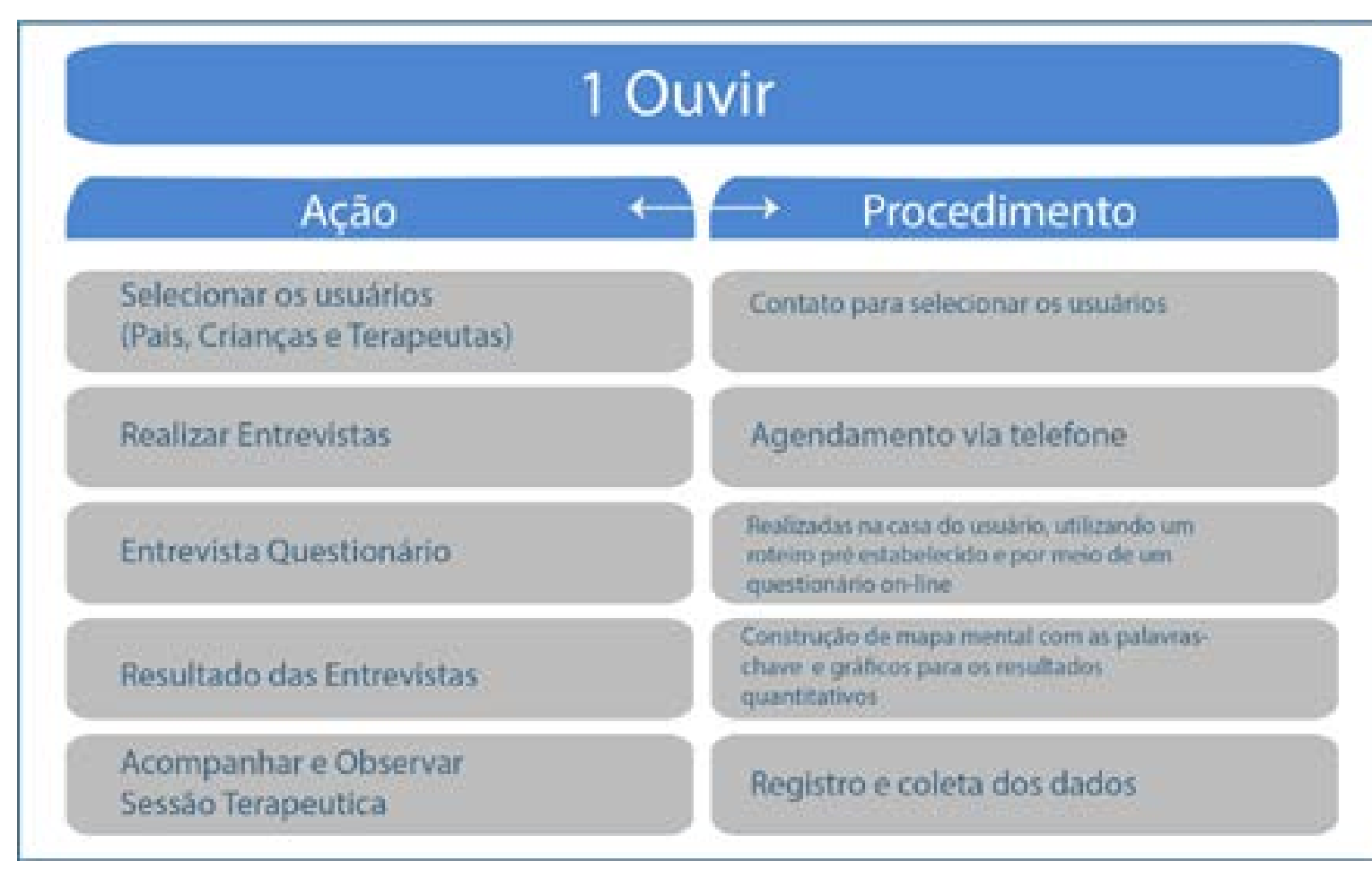

Fonte: primária

Como entrevistados, foram delimitadas crianças com idade entre 1 e 10 anos com autismo de grau leve e moderado, verbais e não verbais, e os pais, moradores da Região Norte e Vale do Itapocú no Estado de Santa Catarina. A região escolhida foi definida a partir da localização residencial da acadêmica pesquisadora.

A faixa etária selecionada para a pesquisa é considerada a fase em que o autismo é descoberto e percebido pelos pais, o que permite uma abordagem social e recomendada para o início das intervenções. O grau leve e moderado do autismo foi selecionado por permitir interações sociais e possuir reações; verbais e não verbais por ser indiferente à pesquisa o fato de existir comunicação oral e/ou gestual.

A ferramenta utilizada inicialmente foi a entrevista, com base em um roteiro pré-estabelecido. Foram entrevistadas 5 famílias $^{2}$ e somente participaram os pais e as crianças que assinaram o termo de consentimento livre e esclarecido (TCLE). Por se tratar de uma pesquisa com seres humanos, a mesma foi submetida ao Comitê de Ética e aprovado com o protocolo $n^{\circ} 81167917.6 .0000 .5366$. As entrevistas foram realizadas na casa dos participantes, com os pais e a criança no mesmo ambiente, para uma abordagem mais natural e menos cansativa, além de conhecer o espaço e as limitações enfrentadas.

Aferramenta deobservação do comportamento foi realizada noacompanhamento de uma sessão terapêutica de uma ${ }^{3}$ criança autista, juntamente com a profissional mediadora e pais, cujo registro foi realizado por meio de fotos e vídeos. Zanelli (2002) acredita que os métodos de observação são úteis para a compreensão de comportamentos e acontecimentos no momento em que eles acontecem, sem que 2 Número de famílias definido pela dificuldade de acesso à pais com crianças autistas, medo e receio das famílias em participar

3 Teve-se autorização de uma família para acompanhar a sessão terapêutica; 
ocorra intervenção de documentos ou pessoas. A observação permite uma atenção aos detalhes e posiciona o pesquisador no cenário em que ele pode compreender a complexidade psicossocial do ambiente, além de proporcionar uma interlocução mais eficaz. O autor comenta que em uma análise de comportamentos e percepções de atitudes não verbais, a técnica de observação é mais adequada e pode ser simples ou utilizar instrumentos de apoio.

Os dados coletados durante as entrevistas e a observação foram analisados por meio da técnica de Análise de Conteúdo. Segundo Moraes (1999) a análise de conteúdo consiste na interpretação das informações verbais e não verbais e faz parte da busca teórica e prática, uma abordagem metodológica com características próprias. Essa técnica permite a interpretação de conteúdo de toda a classe de documentos, que analisados de forma correta apresentam aspectos da investigação social, que de outra forma, seriam inacessíveis.

Moraes (1999) estrutura o método em 5 etapas: preparação das informações, unitarização, categorização, descrição do conteúdo e interpretação dos dados. A seguir são apresentados os dados interpretados durante as entrevistas e a observação.

\section{Resultados e Discussão}

Este tópico apresenta os resultados obtidos na pesquisa de campo, realizada por meio de entrevistas e observação. A primeira entrevista realizada foi com a psicóloga. Os dados gravados em áudio durante a entrevista foram transcritos, analisados e são apresentados em tópicos no quadro 1.

Quadro 1: Percepções entrevista com a psicóloga

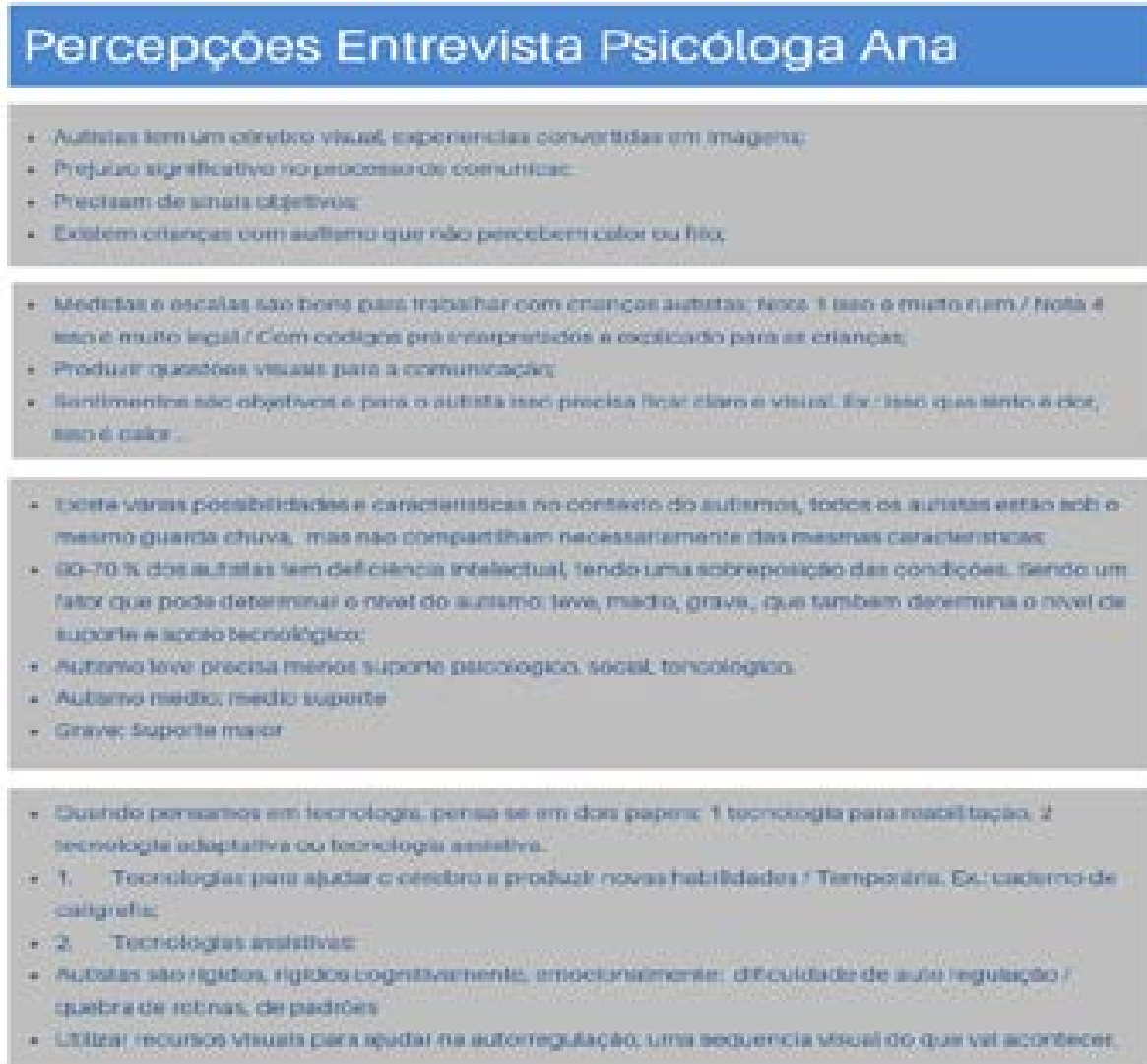

Fonte: primária
Foram realizadas entrevistas com 5 famílias de crianças autistas, com idades características diferentes. O Quadro 2 apresenta as informações referentes a cada família.

\begin{tabular}{|l|l|l|}
\multicolumn{2}{l}{ Quadro 2 } & - Informações famílias entrevistadas \\
\hline Família & Idade Criança & Caracterização Autismo \\
\hline Família 1 & 3 anos & Autismo Verbal - Grau Leve \\
\hline Família 2 & 4 anos & Autismo Não verbal - Grau Leve \\
\hline Família 3 & 5 anos & Autismo Não verbal - Grau Leve \\
\hline Família 4 & 7 anos & Autismo Verbal - Grau Leve \\
\hline Família 5 & 5 anos & Autismo Não verbal - Grau Leve \\
\hline
\end{tabular}

Fonte: primária

Os áudios das entrevistas foram transcritos e analisados, os dados foram sintetizados e apresentados em 4 categorias: Vestuário, Comunicação, Sensibilidade e Estímulos e Comportamento, conforme quadro 3.

\begin{tabular}{|c|c|c|c|}
\hline \multicolumn{4}{|c|}{ Quadro 3: Síntese dos dados das entrevistas } \\
\hline Vestuário & Comunicação & $\begin{array}{l}\text { Sensibilidade e } \\
\text { Estímulos }\end{array}$ & Comportamento \\
\hline $\begin{array}{l}\text { Bom retorno com } \\
\text { a compressão e } \\
\text { uso de roupas } \\
\text { justas }\end{array}$ & $\begin{array}{l}\text { Não consegue } \\
\text { apontar o que } \\
\text { quer ou precisa }\end{array}$ & $\begin{array}{l}\text { Necessita de toque } \\
\text { / pressão }\end{array}$ & Autoagressão \\
\hline $\begin{array}{l}\text { Roupas sem } \\
\text { etiqueta }\end{array}$ & $\begin{array}{l}\text { Agressão } \\
\text { por não ser } \\
\text { compreendido }\end{array}$ & $\begin{array}{l}\text { Busca estímulos / } \\
\text { toque grosseiro }\end{array}$ & $\begin{array}{l}\text { Orientação por } \\
\text { tonalidade de cor, } \\
\text { tamanho e textura }\end{array}$ \\
\hline $\begin{array}{l}\text { Não utilizar tecidos } \\
\text { ásperos }\end{array}$ & $\begin{array}{l}\text { Dificuldade de } \\
\text { comunicação - } \\
\text { não verbal }\end{array}$ & $\begin{array}{l}\text { Sente a mudança } \\
\text { de temperatura, } \\
\text { mas não verbaliza }\end{array}$ & $\begin{array}{l}\text { Não sabia a função } \\
\text { da mão em seu } \\
\text { corpo. }\end{array}$ \\
\hline \multirow{2}{*}{$\begin{array}{l}\text { Dificuldade com } \\
\text { roupas - peças que } \\
\text { não quer utilizar } \\
\text { Roupas sem } \\
\text { costura }\end{array}$} & \multirow{2}{*}{$\begin{array}{l}\text { Uso de recursos } \\
\text { visuais para } \\
\text { tarefas diárias } \\
\text { Não se } \\
\text { comunicava até } \\
\text { os } 2 \text { anos de } \\
\text { idade }\end{array}$} & $\begin{array}{l}\text { Gosta de texturas / } \\
\text { toque }\end{array}$ & $\begin{array}{l}\text { Leve reação a } \\
\text { quebra de rotinas }\end{array}$ \\
\hline & & $\begin{array}{l}\text { Demonstra calor } \\
\text { e frio, mas tem } \\
\text { problemas de } \\
\text { sensibilidade }\end{array}$ & $\begin{array}{l}\text { Fica irritado } \\
\text { quando ocioso }\end{array}$ \\
\hline $\begin{array}{l}\text { Algumas cores } \\
\text { "doem" }\end{array}$ & & $\begin{array}{l}\text { Dificuldade } \\
\text { sensorial - } \\
\text { hiposensível }\end{array}$ & $\begin{array}{l}\text { Observação do } \\
\text { giro dos objetos }\end{array}$ \\
\hline \multirow{3}{*}{$\begin{array}{l}\text { Intolerância } \\
\text { a texturas de } \\
\text { tecidos: Tactel, } \\
\text { Etiquetas, Piquet }\end{array}$} & & $\begin{array}{l}\text { Busca estímulos - } \\
\text { gosta de texturas }\end{array}$ & Se auto desafia \\
\hline & & Precisa do toque & $\begin{array}{l}\text { Limitação na } \\
\text { alimentação }\end{array}$ \\
\hline & & $\begin{array}{l}\text { Aperto } \\
\text { proporciona } \\
\text { concentração }\end{array}$ & \\
\hline
\end{tabular}

Fonte: primária

HFD, v.9, n 17, p. 122-136, junho 2020 
Como parte da pesquisa de campo, houve o acompanhamento de uma sessão terapêutica de uma criança com autismo de grau leve e não verbal. A sessão aconteceu na casa dos pais do participante e a pesquisadora apenas observou os procedimentos sem intervenção na ação. A terapeuta iniciou apresentando a pasta de atividades (FIGURA 2), em que estavam inseridas várias ilustrações representando ações do cotidiano da criança, como comer e beber água.

Figura 2: Pasta com ilustração das atividades para a criança autista
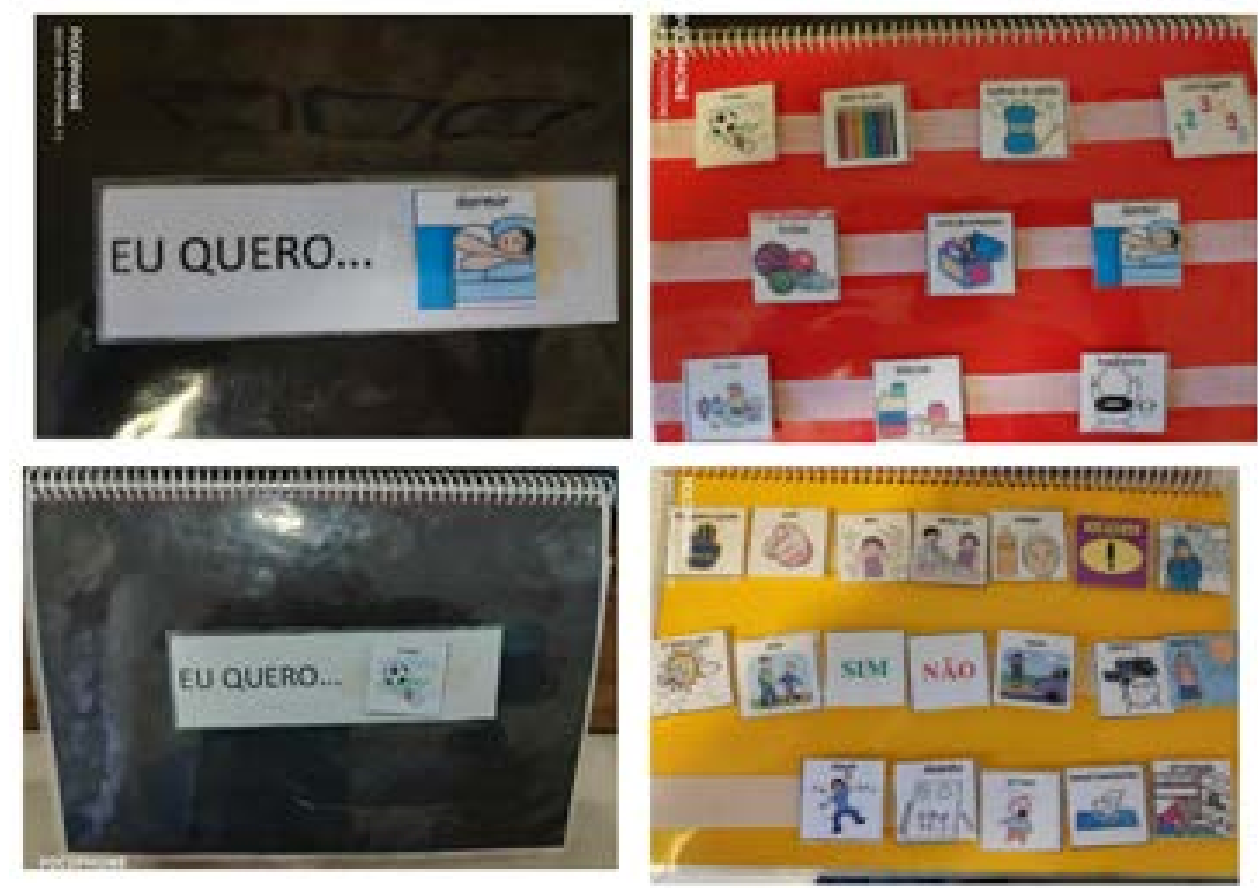

Fonte: primária

Outras atividades foram desenvolvidas pela terapeuta, sendo todas intervenções no desenvolvimento cognitivo, sensorial e motor da criança. Brincadeiras com montagem de letras e jogos divertidos estimulam o participante a compreender situações do cotidiano, como organização do armário e identificação de objetos. A figura 3 ilustra algumas das atividades aplicadas na sessão terapêutica.
Figura 3: Atividades da sessão terapêutica com a criança autista
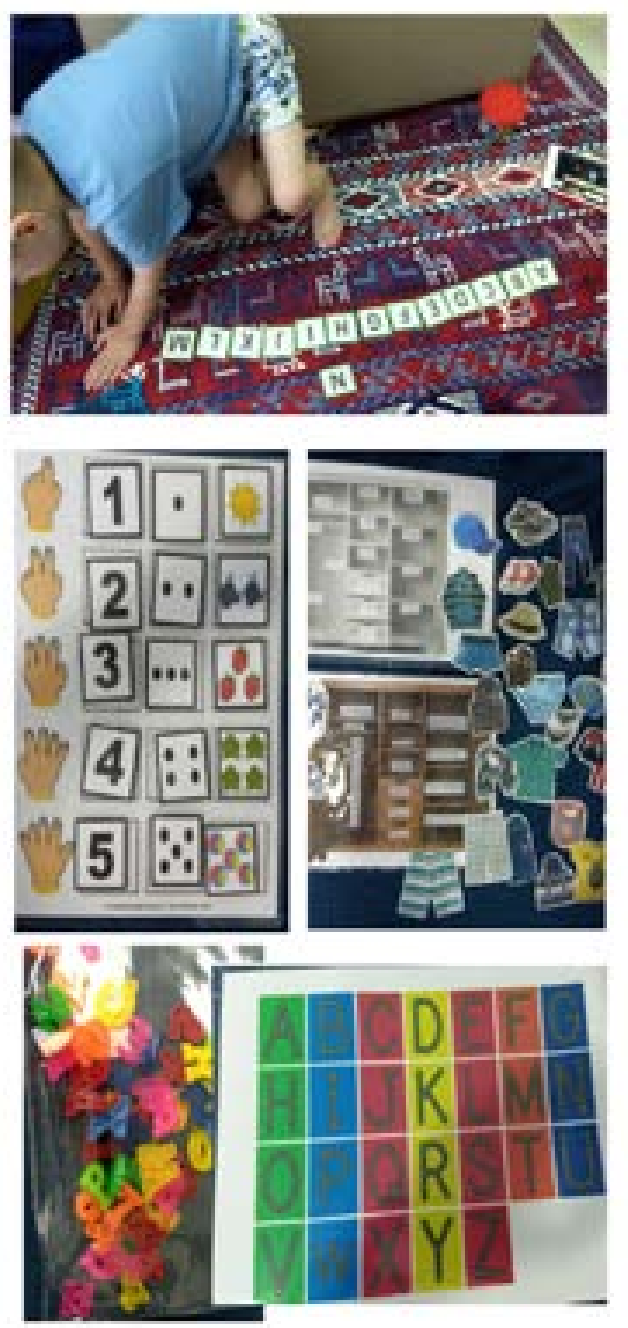

Fonte: (WICK, 2019)

A técnica da observação na pesquisa de campo foi fundamental para perceber as atividades de estímulos junto à criança autista. Segundo o método do HCD (IDEO, 2009), é necessário transformar as pesquisas em soluções por meio de um processo de síntese e interpretação, em que é preciso filtrar e selecionar a informação para transformar insights da realidade em oportunidades.

Os dados coletados em campo foram analisados e interpretados. Os termos estão listados de acordo com a frequência que foram citados nas entrevistas e assim percebidos alguns insights relacionados às dificuldades relatadas pelos pais das crianças autista, apresentados no infográfico (FIGURA 4). 
Figura 4: Insigths

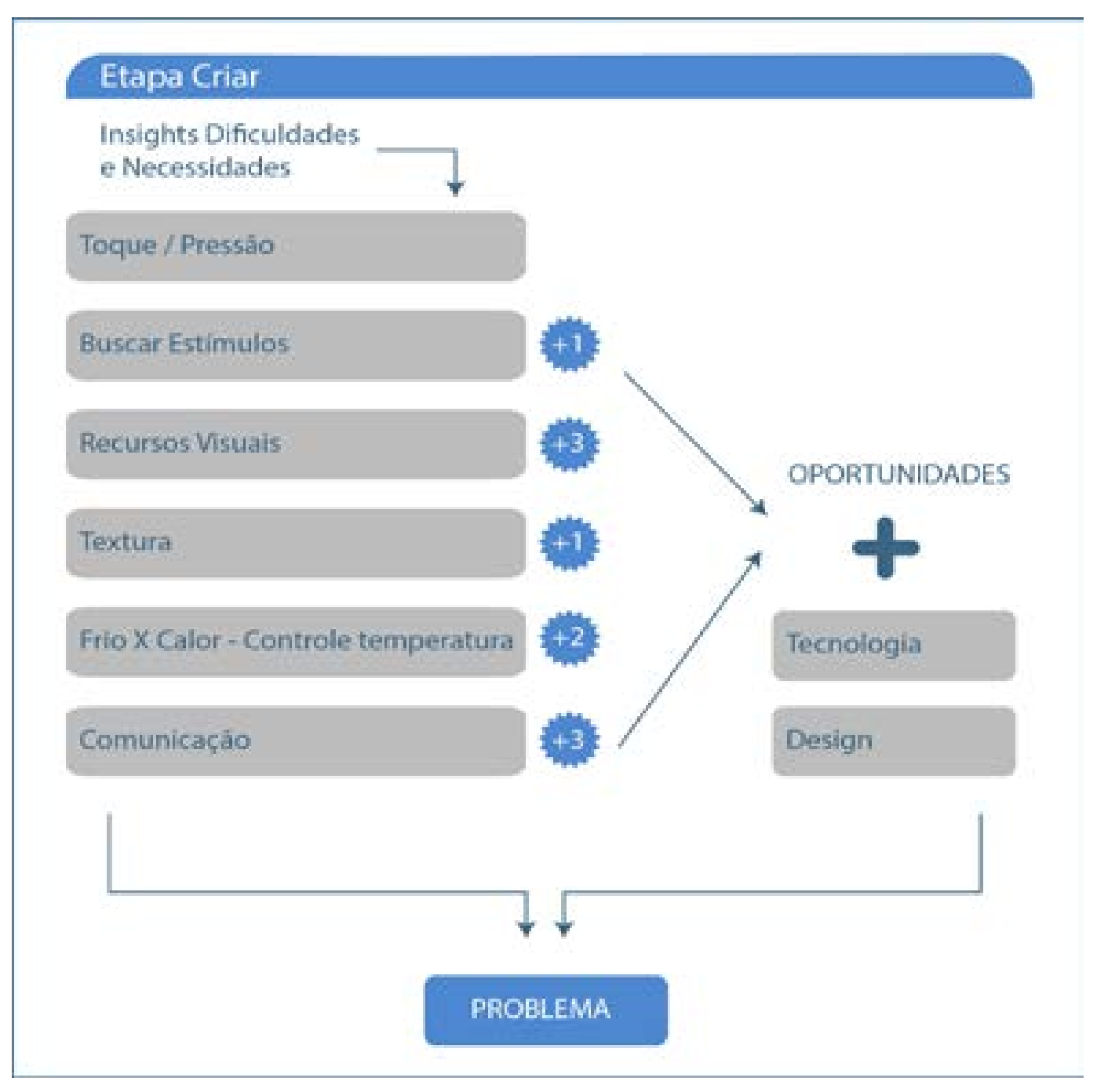

Fonte: primária

Os insights sinalizados foram categorizados e direcionados para criação de oportunidades, aliados à tecnologia e design. Com base nos resultados da etapa Ouvir, foram definidas diretrizes de projeto para o desenvolvimento de dispositivos de computação vestível direcionado às crianças autistas. Dessa maneira, são descritos na figura 5 os requisitos para um dispositivo vestível que auxilie a criança autista e/ou seu pai ou responsável no processo de comunicação, monitoramento de temperatura e estímulos.
Figura 5: Lista de requisitos do dispositivo

\begin{tabular}{|c|c|}
\hline Requisito & Classificação \\
\hline $\begin{array}{l}\text { Estar vestido so corpo ou anexado } \\
\text { a roupa / acessorio }\end{array}$ & Necessário \\
\hline Interface Intuitiva & Necessário \\
\hline Utilizar cores adequadas & Desejivel \\
\hline Estetica atrativa e amigável & Necessario \\
\hline Formas Suaves & Desejável \\
\hline $\begin{array}{l}\text { Funçoes de controle e monitoramento } \\
\text { de temperatura corporal }\end{array}$ & Necessário \\
\hline Promover estimulos sensoriais & Necessärio \\
\hline $\begin{array}{l}\text { Ser adaptavel para a situaçáo da } \\
\text { criança }\end{array}$ & Necessitrio \\
\hline $\begin{array}{l}\text { Emitir sons e luzes de forma suave, } \\
\text { que nâo agrida visualmente }\end{array}$ & Necessatrio \\
\hline $\begin{array}{l}\text { Permitir o controle do dispositivo por } \\
\text { parte do pai ou responsavel }\end{array}$ & Necessärio \\
\hline Conexäo com Smartphones, Tablets & Necessário \\
\hline $\begin{array}{l}\text { Promover microvibraçöes suavese } \\
\text { hápticas }\end{array}$ & Desejaivel \\
\hline $\begin{array}{l}\text { Minimizar os efeitos de crises de } \\
\text { ansiedade, por melo de estimulos }\end{array}$ & Necessatrio \\
\hline $\begin{array}{l}\text { Facilitar a interaçáo e comunicaçà } \\
\text { entre a criança e seu paí ou responsável }\end{array}$ & Necessário \\
\hline Ser durável e seguro para o usuário & Necessario \\
\hline $\begin{array}{l}\text { Controle das funç̧̄es por meio de } \\
\text { aplicativos }\end{array}$ & Necessario \\
\hline
\end{tabular}

Fonte: primária 
A lista de requisitos estabelece o início do processo de criação, cujos atributos listados são transformados em conceitos para idealização de uma proposta. A partir dos requisitos foram definidas quatro categorias: Usabilidade, Materiais e Textura, Estética e Função, conforme figura 6.

Figura 6: Atributos do Produto

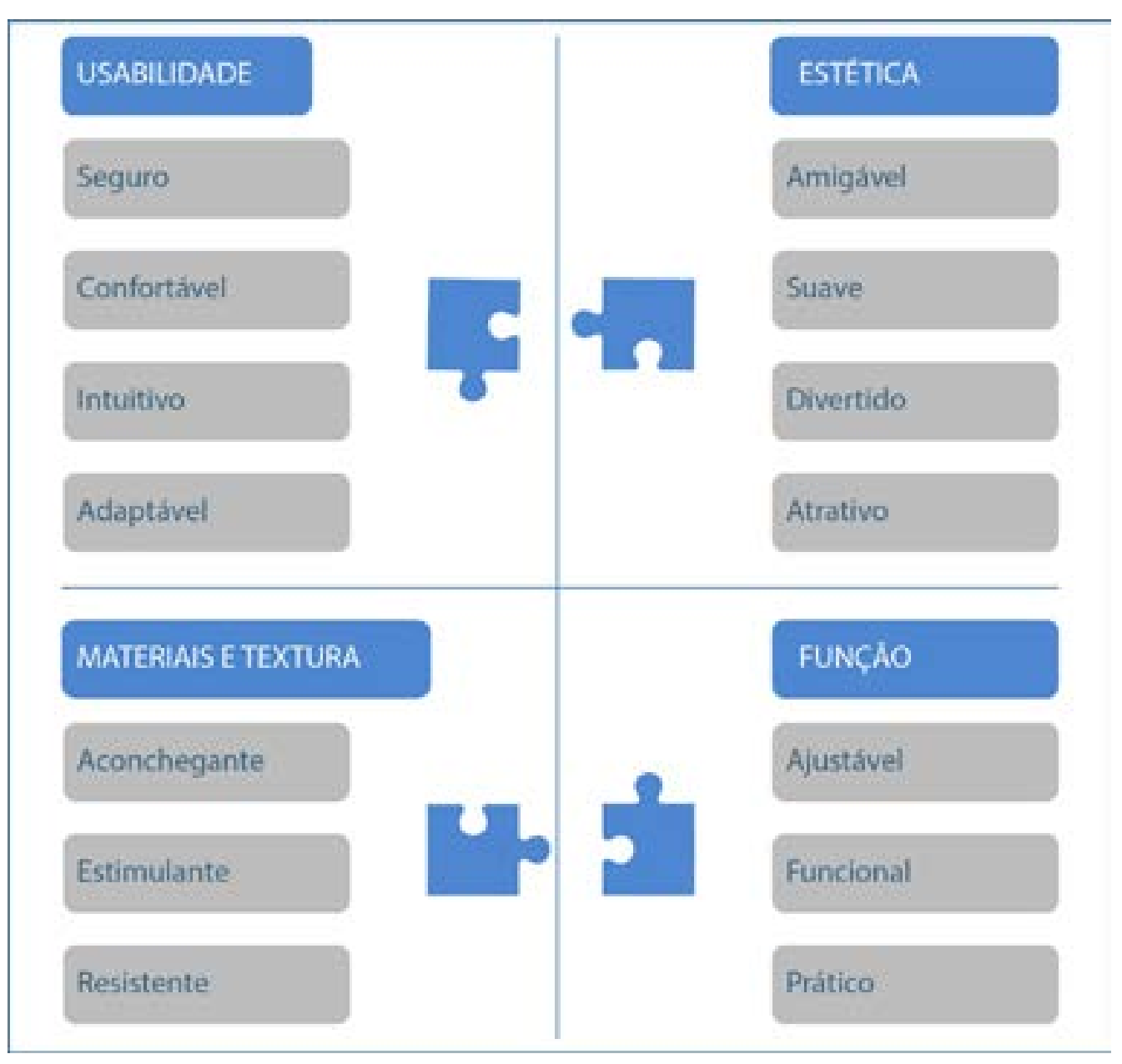

Fonte: primária

O resultado da pesquisa de campo com os usuários, sintetizados em requisitos de projeto e atributos de produto, serviu de base para concepção de uma proposta conceitual de dispositivo vestível para crianças autistas, desenvolvida posteriormente na etapa Criar. Ao projetar para este público, o designer deve considerar que cada indivíduo autista é único, e que o transtorno acomete o desenvolvimento de formas diferentes, devendo optar por soluções personalizáveis de acordo com a necessidade do usuário. A abordagem do Design Centrado no Humano permitiu identificar as necessidades reais de cada indivíduo e envolvê-los no processo de construção da solução.

\section{Considerações Finais}

A pesquisa realizada foi fundamental para o entendimento do transtorno da percepção inicial das dificuldades, sintomas e a singularidade na forma como o autismo se manifesta. Olhar o contexto e enxergar com sensibilidade as necessidades e dificuldades é fundamental para propor soluções que facilitem o cotidiano dos indivíduos com TEA.

A etapa Ouvir da abordagem do DHC foi essencial para desbravar uma área desconhecida pela acadêmica e compreender fatores associa dos ao autismo, auxiliando assim na definição do problema de pesquisa quanto as dificuldades e necessidades reais de uma criança autista, entender a singularidade do autismo, como se manifesta de formas diferentes em cada criança e perceber o grande desafio para encontrar uma similaridade e obter sugestões passíveis de solução a partir da participação dos usuários, pais e responsáveis.

As entrevistas e a observação revelaram um cenário desafiador, com poucas opções de produtos para auxiliar as crianças autistas, a dificuldade dos pais com o cotidiano de seus filhos autistas, além de enfrentar a ignorância das pessoas pela falta de conhecimento em relação as manifestações do autismo. Durante a observação da sessão terapêutica, percebeu-se a importância das intervenções para o desenvolvimento e evolução das habilidades cognitivas e sensoriais. A criatividade da terapeuta no momento da sessão, ao adaptar objetos e brincadeiras para a realização da mediação, demonstrou uma oportunidade pela falta de aparatos para tratamentos e intervenções junto a criança autista.

O processo proporcionou uma experiência e um aprendizado profundo sobre - cotidiano de crianças autistas, que comprovaram as atitudes e comportamentos apontados por autores estudados na revisão bibliográfica. Foi possível também imergir em um processo empático e sentir as frustrações e alegrias relatadas pelos pais a cada conquista do seu filho autista. Os dados foram válidos para identificar algumas necessidades das crianças autistas e contribuíram para definir requisitos de projeto e atributos essenciais para o desenvolvimento de artefatos de computação vestível destinado ao auxílio de pessoas com necessidades especiais, os quais consideram para além das soluções formais, estéticas e tecnológicas, os aspectos subjetivos, emocionais e perceptivos que ofereçam qualidade de vida aos usuários. Os requisitos de foram aplicados na concepção de uma proposta conceitual de computação vestível, que foi prototipada e validada junto aos usuários. 


\section{Referências}

Abras, C., Maloney-Krichmar, D., Preece, J. (2004). User Centered Design. In BAINBRIDGE, W. Encyclopedia of Human-Computer Interaction. Thousand Oaks: Sage Publications, 2004. Disponível em: <http://citeseerx.ist.psu.edu/viewdoc/ download?doi=10.1.1.94.381\&rep=rep1\&type=pdf>. Acesso em 11. Jan.19

GARRET, Jesse James. The Elements of user experience: user-centered design for the web and beyound. 2. ed. Berkeley: New Riders, 2010.

GAUDERER, C. Autismo e Outros Atrasos do Desenvolvimento. $2^{\mathrm{a}}$ Ed. São Paulo: Revinter Livraria E It, 1997.

IBGE. Censo Demográfico 2010. Disponível em < https://www.ibge.gov.br/estatisticasnovoportal/sociais/saude/9662-censo-demografico-2010.html> Acesso em 20.abr.17

IDEO. HCD - Human Centered Design: Kit de ferramentas. EUA: Ideo, 2009. $102 \mathrm{p}$ Disponível em: <http://www.ideo.com/work/human-centered-design-toolkit/>. Acesso em 24.mar.18.

Infopedia - Disponível em <https://www.infopedia.pt/dicionarios/lingua-portuguesa/ ecolalia> . Acesso: 22/04/2019

KRIPPENDORF, K. Design centrado no usuário: uma necessidade cultural. Estudos em Design, Rio de Janeiro, v. 8, n. 3, p. 87-98, 2000.

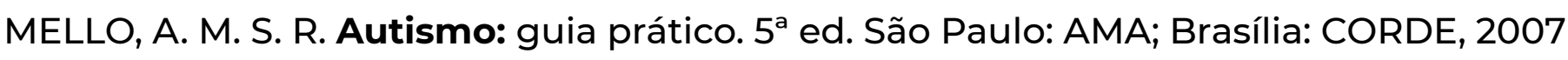

MELLO, A. M. S. R. Autismo: guia prático. $4^{\text {a }}$ ed. São Paulo: AMA; Brasília:

CORDE, 2004

MORAES, Roque. Análise de conteúdo. Revista Educação, Porto Alegre, v. 22, n. 37, p. 7-32, 1999

NAOE, Aline. Tecnologia pode ajudar no tratamento de pessoas com autismo. 2012 DICYT. Disponível em <http://www.dicyt.com/viewNews.php? newsld=24139> Acesso em 30 Dez.2018

ONUBR. Especialistas da ONU em direitos humanos pedem fim da discriminação contra pessoas com autismo. 2016. Disponível em: <https://nacoesunidas.org/ especialistas-em-direitos-humanos-da-onu-pedem-fim-da-discriminacao-contrapessoas-com-autismo/>. Acesso em: 07 jun. 2018.

PINHO, MÁrcia Andrade. MANIFESTAÇÕES GASTROINTESTINAIS EM CRIANÇAS COM TRANSTORNO DO ESPECTRO AUTISTA. 2015. 162 f. Tese (Doutorado) - Curso de Processos Interativos dos Órgãos e Sistemas, Universidade Federal da Bahia, Salvador 2015. Disponível em: <https://repositorio.ufba.br/ri/bitstream/ri/20963/1/MARCIA\%20 A\%2OPINHO\%2OTESE.pdf\%2OTESE\%2ODOUTORADO.pdf>. Acesso em: 07 jun. 2018.
SILVA, A. B. B. Mundo singular: entenda o autismo. Rio de Janeiro: Objetiva, 2012

SCHWARTZMAN, J. Autismo Infantil. São Paulo: Memnom Edições Científicas Ltda, 2003

VYGOTSKY, L. A formação social da mente. São Paulo: Martins Fontes, 1987

ZANELLI, J. C. Pesquisa qualitativa em estudos da gestão de pessoas. Estudos de Psicologia, v. 7, p. $79-88,2002$ 